University of Nebraska - Lincoln

DigitalCommons@University of Nebraska - Lincoln

USDA National Wildlife Research Center - Staff Publications
U.S. Department of Agriculture: Animal and Plant Health Inspection Service

2013

\title{
Use of patch selection models as a decision support tool to evaluate mitigation strategies of human-wildlife conflict
}

\author{
Sharon Baruch-Mordo \\ Colorado State University, sbaruch-mordo@tnc.org \\ Colleen T. Webb \\ Colorado State University, Colleen.Webb@ColoState.EDU \\ Stewart W. Breck \\ USDA/APHIS/WS National Wildlife Research Center, stewart.w.breck@aphis.usda.gov \\ Kenneth R. Wilson \\ Colorado State University, kenneth.wilson@colostate.edu
}

Follow this and additional works at: https://digitalcommons.unl.edu/icwdm_usdanwrc

Part of the Life Sciences Commons

Baruch-Mordo, Sharon; Webb, Colleen T.; Breck, Stewart W.; and Wilson, Kenneth R., "Use of patch selection models as a decision support tool to evaluate mitigation strategies of human-wildlife conflict" (2013). USDA National Wildlife Research Center - Staff Publications. 1224.

https://digitalcommons.unl.edu/icwdm_usdanwrc/1224

This Article is brought to you for free and open access by the U.S. Department of Agriculture: Animal and Plant Health Inspection Service at DigitalCommons@University of Nebraska - Lincoln. It has been accepted for inclusion in USDA National Wildlife Research Center - Staff Publications by an authorized administrator of DigitalCommons@University of Nebraska - Lincoln. 


\title{
Use of patch selection models as a decision support tool to evaluate mitigation strategies of human-wildlife conflict
}

\author{
Sharon Baruch-Mordo ${ }^{\mathrm{a}, \mathrm{b}}$, Colleen T. Webb ${ }^{\mathrm{c}, \mathrm{b}}$, Stewart W. Breck ${ }^{\mathrm{d}}$, Kenneth R. Wilson ${ }^{\mathrm{a}, \mathrm{b}}$ \\ ${ }^{a}$ Department of Fish, Wildlife, and Conservation Biology, Colorado State University, Fort Collins, CO 80523, \\ United States \\ ${ }^{\mathrm{b}}$ Graduate Degree Program in Ecology, Colorado State University, Fort Collins, CO 80523, United States \\ ${ }^{\mathrm{c}}$ Department of Biology, Colorado State University, Fort Collins, CO 80523, United States \\ ${ }^{\mathrm{d}}$ USDA-WS-National Wildlife Research Center, Fort Collins, CO 80521, United States
}

\begin{abstract}
Human-dominated landscapes offer spatially concentrated and reliable food resources that attract wildlife and lead to human-wildlife conflicts. Conflict management is often directed at humans (e.g., education) to reduce attractants, or foraging benefits to wildlife, or at wildlife (e.g., hazing) to increase foraging costs; but strategies can be expensive and ineffective. Because a key driver of conflict is the pursuit of food by wildlife, we used patch selection models, a dynamic, state-dependent modeling approach based on foraging theory, to assess how benefit reduction and cost increase resulting from conflict mitigation affect wildlife foraging decisions. We applied the patch selection models to a system in which American black bears (Ursus americanus) forage in urban and urban-interface patches and conflicts are common. We used survival as a fitness currency and body fat reserves as a state variable. We incrementally reduced availability of anthropogenic foods (benefit reduction) and increased energetic costs of movement in response to aversive conditioning treatments (cost increase) to search for thresholds resulting in avoidance of human-dominated patches. Benefit reduction $\geqslant 55 \%$ in urban patches and $\geqslant 70 \%$ in urban-interface patches resulted in avoidance by bears of almost all states. Cost increases achieving similar results exceeded 1100\% and $400 \%$ in urban and urban-interface patches respectively, and are likely unrealistic to implement. Given modeling results and that control strategies targeting wildlife are unpopular with constituencies, we suggest allocating management resources to strategies that reduce availability of anthropogenic food.
\end{abstract}

Keywords: American black bear, Aversive conditioning treatments, Foraging theory, Urban ecology, Ursus americanus 


\title{
Use of patch selection models as a decision support tool to evaluate mitigation strategies of human-wildlife conflict
}

\author{
Sharon Baruch-Mordo ${ }^{\mathrm{a}, \mathrm{b}, *}$, Colleen T. Webb ${ }^{\mathrm{c}, \mathrm{b}}$, Stewart W. Breck ${ }^{\mathrm{d}}$, Kenneth R. Wilson ${ }^{\mathrm{a}, \mathrm{b}}$ \\ ${ }^{a}$ Department of Fish, Wildife, and Conservation Biology, Colorado State University, Fort Collins, CO 80523, United States \\ ${ }^{\mathrm{b}}$ Graduate Degree Program in Ecology, Colorado State University, Fort Collins, CO 80523, United States \\ ${ }^{\mathrm{c}}$ Department of Biology, Colorado State University, Fort Collins, CO 80523, United States \\ ${ }^{\mathrm{d}}$ USDA-WS-National Wildlife Research Center, Fort Collins, CO 80521, United States
}

\section{A R T I C L E I N F O}

\section{Article history:}

Received 7 September 2012

Received in revised form 6 January 2013

Accepted 7 February 2013

Available online 22 March 2013

\section{Keywords:}

American black bear

Aversive conditioning treatments

Foraging theory

Urban ecology

Ursus americanus

\begin{abstract}
A B S T R A C T
Human-dominated landscapes offer spatially concentrated and reliable food resources that attract wildlife and lead to human-wildlife conflicts. Conflict management is often directed at humans (e.g., education) to reduce attractants, or foraging benefits to wildlife, or at wildlife (e.g., hazing) to increase foraging costs; but strategies can be expensive and ineffective. Because a key driver of conflict is the pursuit of food by wildlife, we used patch selection models, a dynamic, state-dependent modeling approach based on foraging theory, to assess how benefit reduction and cost increase resulting from conflict mitigation affect wildlife foraging decisions. We applied the patch selection models to a system in which American black bears (Ursus americanus) forage in urban and urban-interface patches and conflicts are common. We used survival as a fitness currency and body fat reserves as a state variable. We incrementally reduced availability of anthropogenic foods (benefit reduction) and increased energetic costs of movement in response to aversive conditioning treatments (cost increase) to search for thresholds resulting in avoidance of human-dominated patches. Benefit reduction $\geqslant 55 \%$ in urban patches and $\geqslant 70 \%$ in urban-interface patches resulted in avoidance by bears of almost all states. Cost increases achieving similar results exceeded $1100 \%$ and $400 \%$ in urban and urban-interface patches respectively, and are likely unrealistic to implement. Given modeling results and that control strategies targeting wildlife are unpopular with constituencies, we suggest allocating management resources to strategies that reduce availability of anthropogenic food.
\end{abstract}

(c) 2013 Elsevier Ltd. All rights reserved.

\section{Introduction}

Human-wildlife interactions, and subsequently conflicts, are increasing worldwide (Conover, 2001; Woodroffe et al., 2005). Human-dominated landscapes offer spatially concentrated, predicable, and reliable food sources, e.g., livestock, crops, or refuse, which can serve as major attractants to wildlife and lead to human-wildlife conflict (Shochat, 2004; Baker et al., 2008). Whether the resultant conflict occurs due to depredation of livestock in South America (e.g., Michalski et al., 2006), raiding of agricultural corps in Europe (e.g., Geisser and Reyer, 2004), or use of refuse in urban centers in North America (e.g., Beckmann and Berger, 2003), a key driver of conflict is the pursuit of food resources by wildlife. Thus, understanding how to best mitigate human-wildlife conflict requires an understanding of how management affects wildlife foraging decisions.

\footnotetext{
* Corresponding author at: The Nature Conservancy, Fort Collins, CO 80524, United States. Tel.: +1 970484 9598; fax: +1 9704980225 .

E-mail address: sbaruch-mordo@tnc.org (S. Baruch-Mordo).
}

Two major management strategies aimed at humans and wildlife are commonly employed to resolve conflicts. Human-dimensions tools are implemented in conflict communities to change human behavior to reduce the availability of attractants, or foraging benefits, to wildlife. For example, improving husbandry through education reduced livestock depredation by snow leopards (Panthera uncia) in India (Jackson and Wangchuk, 2004), and proactively enforcing refuse disposal laws reduced availability of garbage to American black bears (Ursus americanus) in Colorado, USA (Baruch-Mordo et al., 2011). Wildlife management tools are also implemented to either eliminate (lethal control) or deter (non-lethal control) wildlife from attractant sites (Fall and Jackson, 2002; Treves and Karanth, 2003). Lethal control can be unpopular with wildlife managers (e.g., Fall and Jackson, 2002; Baker et al., 2005; Spencer et al., 2007), often motivated by the unpopularity of such management actions by the general public (Manfredo, 2008; Messmer, 2009). Therefore, wildlife agencies are increasingly using non-lethal aversive conditioning treatments, including hazing, and chemical or physical deterrents, with the goal of modifying the long-term behavior of wildlife due to the learning 
process of aversive conditioning (Hopkins et al., 2010). Aversive conditioning treatments offer a source of discomfort or pain to wildlife that often invokes a flight response (Shivik et al., 2003; Mazur, 2010) and consequently increases the energetic costs of foraging in human-dominated areas. Examples include hazing of African elephants (Loxodonta africana) with fire and noise to reduce crop raiding in Kenya (Sitati et al., 2005), and using chemical repellents to deter badgers (Meles meles) from crops in Europe (Baker et al., 2005). Put in the context of foraging decision making by wildlife, conflict management strategies targeting humans and wildlife aim to either decrease wildlife foraging benefits, or conversely, increase wildlife foraging costs that are associated with human-dominated areas.

Conflict management can be expensive and ineffective, and it is generally believed that management cannot successfully eliminate all attractants or deter all individuals (Linnell et al., 1997; Treves and Karanth, 2003; Mazur, 2010; Baruch-Mordo et al., 2011). Consequently, there is a need to determine which management strategy, or which combinations, are most effective in altering wildlife foraging decisions. Patch selection models (Mangel and Clark, 1986) provide a framework to test how benefit reduction and cost increase influence wildlife foraging decisions. Under this approach, patches can be considered as human-dominated or not, and patch selection by wildlife can be optimized based on patch-specific benefits and costs given the energy reserves of the animal (Mangel and Clark, 1986). One can evaluate the effects of conflict management on wildlife foraging decisions by using sensitivity analysis where benefits and costs in human-dominated patches are systematically varied and the impacts on foraging choices are determined. One can also search for thresholds of benefit reduction and cost increase beyond which wildlife no longer select human-dominated patches, thus providing guidelines for conflict mitigation.

In this paper we demonstrated the application of patch selection models in conservation management. We examined how changes in foraging costs and benefits incurred from the management of human-bear conflicts can influence the foraging decisions of black bears in human-dominated areas. Bears are an ideal organism to use as an example because of the high energetic costs of hibernation, which can lead to conflict with humans over food resources. Bears enter a state of hyperphagia, or intense feeding, in late summer and fall to gain sufficient fat reserves for hibernation (Nelson et al., 1983). If factors such as weather or disease cause the natural food production to fail during hyperphagia, bears will use alternative anthropogenic food sources and forage near human development (Mattson et al., 1992). Consequently, human-bear conflicts increase in poor natural food production years (Zack et al., 2003; Ryan et al., 2007; Baruch-Mordo et al., 2008), and wildlife managers mitigate conflicts by more intensely applying strategies such as education aimed at humans (Baruch-Mordo et al., 2011) or aversive conditioning treatments aimed at bears (Spencer et al., 2007; Honeyman, 2008). We evaluated the effects of such strategies on bear foraging decisions using a patch selection model parameterized from literature and field data. We used the model to search for thresholds of benefit reduction and cost increase beyond which bears would not forage in human-dominated patches to inform the allocation of resources for the management of humanbear conflicts.

\section{Materials and methods}

\subsection{Study system}

We used Aspen, Colorado, USA, located in the central mountains of Colorado, as the model system. The human-dominated area of Aspen consists of a downtown business district and high human density residential areas (urban patch) that are surrounded by lower density residential neighborhoods (urban-interface patch; Fig. 1). Residential neighborhoods are dispersed within mountain-shrub and forest communities that are adjacent to large national forest and wilderness areas (wildland patch). Hyperphagia season in Aspen lasts from approximately 1 August-15 October (total of 75 days), a period when fruit ripens providing important local natural food sources for bears including Gambel oak (Quercus gambelii), serviceberry (Amelanchier alnifolia), and chokecherry (Prunus virginiana). From 2005 to 2010 we deployed GPS collars on bears to better understand their movement patterns and resource use in the urban environment (Baruch-Mordo, 2012). Bears used urban and urban-interface areas extensively during hyperphagia season in years of poor natural food production, a time when conflicts with humans flared. We backtracked to GPS locations in Aspen and identified garbage as the main anthropogenic attractant.

Management strategies applied in Aspen to reduce availability of garbage to bears included targeting humans with education, and the enforcement of local refuse disposal laws. We experimentally evaluated both management tools and found proactive enforcement to be most effective in changing human behavior to better secure garbage (Baruch-Mordo et al., 2011). However, despite observing a reduction in garbage availability following treatment, we did not observe a complete elimination of garbage resources, and in fact, found garbage to be readily available to bears throughout Aspen at all times. Alternative management strategies applied in Aspen to prevent bear use of garbage and therefore reduce human-bear conflicts included non-lethal methods of aversive conditioning treatment. While we did not measure bear response to aversive conditioning treatments as applied in Aspen, the most common response by bears is running away from the source of discomfort (Mazur, 2010), a behavior we commonly observed when treatments were applied.

\subsection{Patch selection model}

Mangel and Clark $(1986,1988)$ developed a general patch selection model based on optimal foraging theory using a state-dependent modeling approach that is solved by dynamic programming. The patch selection model optimizes a fitness function $F(x, t)$, or the maximum fitness from time step $t=1$ to terminal time step $T$ given that the organism was alive at time $t$ and had a state variable value of $X(t)=x$. At each time step fitness is updated as detailed in Eq. (1) below, and the selected patch that maximizes fitness is recorded in a patch decision matrix. We applied the patch selection model to our system using two human-dominated patches (urban and urban-interface) and one nonhuman-dominated patch (wildland). We used survival as the fitness currency, body fat reserves ( $\mathrm{kg}$ fat) as the state variable (Section 2.3), and maximized fitness over the hyperphagia season using day as a discrete time unit $(t=1,2, \ldots, 75)$.

The dynamic state variable $X(t)$ in patch selection models can be constrained between a critical value of $x_{c}$ and cap value of $C$, and the terminal fitness at time $T$ is known and represented by a function $\phi(x)$ such that $F(x, T)=\phi(x)$. We used critical and cap values for $\mathrm{kg}$ fat reserves that were converted from minimum and maximum values reported for body mass $(M)$ of Aspen bears, and we quantified survival as a function of body mass at time $T$ based on an allometric relationship (Section 2.3). Once fitness is known at terminal step $T$, the model can be solved for maximum fitness by backwards iteration using a Markovian decision process (Mangel and Clark, 1986). At each time step fitness is calculated as the probability of survival in period $t$ times the probability of survival from period $t$ to $t+1$, where the latter is composed of survival when food is found plus survival when food is not found. Fitness is maximized 


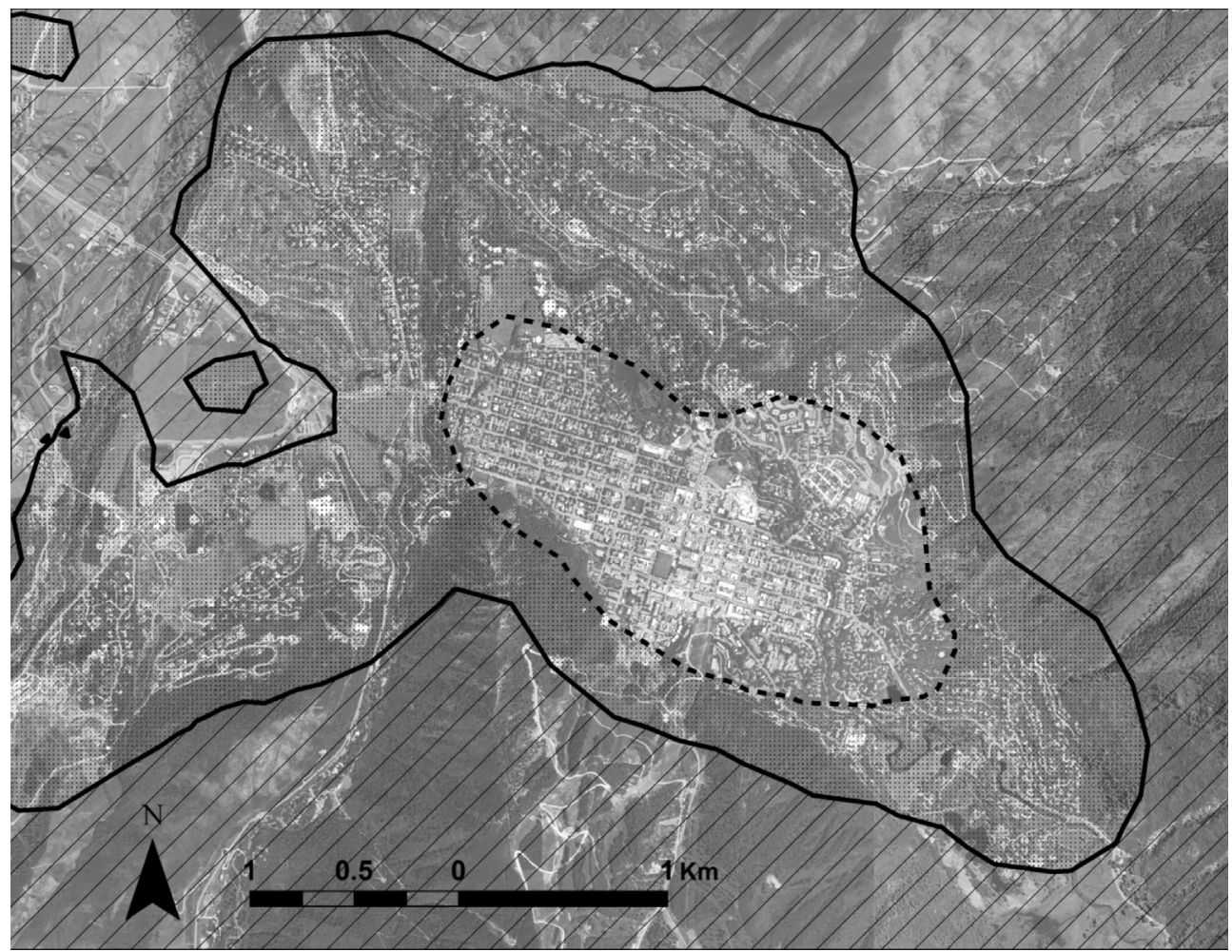

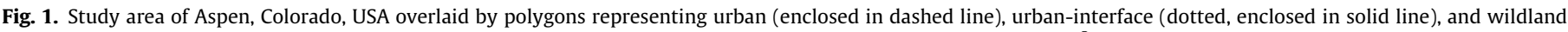
(crossed-hatched) patches. Patches were defined using natural breaks in the distribution of address density per 1 -km ${ }^{2}$ (Appendix C).

across $i$ patches (human-dominated or not) given patch-specific survival $\left(s_{i} ; 1-\beta_{i}\right.$ in Mangel and Clark, 1986, 1988) and the probability of finding food $\left(\lambda_{i}\right)$ according to the equation:

$F(x, t)=\max _{i}\left[s_{i}\left\{\lambda_{i} F\left(x_{i}^{\prime}, t+1\right)+\left(1-\lambda_{i}\right) F\left(x_{i}^{\prime \prime}, t+1\right)\right\}\right]$

where $x_{i}^{\prime}=x-\alpha_{i}+Y_{i}$ and $x_{i}^{\prime \prime}=x-\alpha_{i}$ are functions updating the state variable based on patch-specific foraging costs $\left(\alpha_{i}\right)$ and yields $\left(Y_{i}\right)$ if food is found $\left(x_{i}^{\prime}\right)$, or costs only if food is not found $\left(x_{i}^{\prime \prime}\right)$. We quantified foraging costs as the loss of $\mathrm{kg}$ fat from energetic expenditure on patch-specific movement, and foraging yields as the gain of $\mathrm{kg}$ fat from food found in each patch. If the resultant values of $x_{i}^{\prime}$ or $x_{i}^{\prime \prime}$ are lower than a critical value $x_{c}$ or exceed a cap value $C$, then they were set to the critical or cap value, respectively.

We used an adaptation of the patch selection model in Eq. (1) to consider foraging on $j$ different food types in each $i$ th patch. In this approach, the probability of finding food becomes patchand food type-specific $\left(\lambda_{i j}\right)$, and the probability of not finding food in a patch is inclusive of all food types. Fitness can be maximized using:

$F(x, t)=\max _{i}\left[s_{i}\left\{\sum_{j} \lambda_{i j} F\left(x_{i j}^{\prime}, t+1\right)+\left(1-\sum_{j} \lambda_{i j}\right) F\left(x_{i j}^{\prime \prime}, t+1\right)\right\}\right]$

with the functions specified in Eq. (3) updating the state variable according to whether the animal found food or not. Additional expansion of the simple patch selection model is the inclusion of state-dependent costs, $\alpha_{i}(x)$. If cost is defined as energy lost due to basal metabolic rate, which is a function of body mass $M$, then $\alpha_{i}(x)=57.2 M^{0.716}$ for mammalian species (Robbins, 1993). Redefining yield to be food type-specific and incorporating state-dependency to patch-specific costs, the organism's state can be updated using equations:

$x_{i j}^{\prime}=x-\alpha_{i}(x)+Y_{j}$ $x_{i j}^{\prime \prime}=x-\alpha_{i}(x)$.

We used the adaptations developed in Eqs. (2) and (3) to model bear foraging in Aspen. We defined three patches, urban $(u)$, urbaninterface (ui), and wildland ( $w)$, and two food types, anthropogenic and natural, with an implicit assumption that bears always find and consume both food types according to their availability in each patch (i.e., no food preferences).

\subsection{Model parameterization}

We focused model parameterization on adult females because their survival and reproductive output is necessary to bear population growth (Freedman et al., 2003; Mitchell et al., 2009). We additionally focused on poor natural food production years in which bears are most likely to forage in the urban environment and conflict management strategies are likely to be applied. We note that such conditions might present a worst-case scenario in some systems; however our study system experienced two major natural food failures in the 6-year duration of our field study, making this a more common management scenario. A detailed description and justification for each parameter is provided below and summarized in Table 1.

We used fat reserves as the state variable because fat is crucial for bear winter survival and reproductive success (Belant et al., 2006; Robbins et al., 2007). Bears can lose up to $50 \%$ of their body weight during hibernation (Beecham and Rohlman, 1994) with loss consisting primarily of fat (Farley and Robbins, 1995; Harlow et al., 2002); therefore adequate fat reserves are important for over-winter survival. Additionally, bears reproduce via delayed implantation, where females without adequate fat reserves will not implant the blastocyst and consequently forgo reproduction (Eiler et al., 1989). Finally, females with poor fat reserves can have lower milk production to support cubs, resulting in increased intra-litter 
Table 1

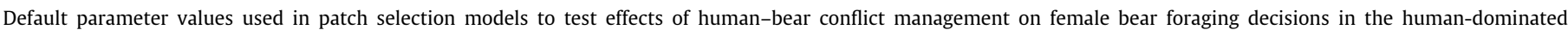
environment of Aspen, Colorado, USA. Patches included were urban $(u)$, urban-interface $(u i)$, and wildland $(w)$.

\begin{tabular}{|c|c|c|c|c|}
\hline Symbol & Interpretation & \multicolumn{2}{|l|}{ Description and default values } & Source \\
\hline$X$ & $\begin{array}{l}\text { State variable of } \\
\text { value } x \text { at time } t\end{array}$ & \multicolumn{2}{|c|}{$\begin{array}{l}\mathrm{kg} \text { of body fat scaled from female body mass assuming } 30 \% \text { body fat. Critical }\left(x_{c}\right) \\
\text { and cap }(C) \text { values of } 20 \text { and } 35 \mathrm{~kg} \text { fat based on data from Aspen study bears }\end{array}$} & $\begin{array}{l}\text { Baruch-Mordo, unpublished data, } \\
\text { Belant et al. (2006) }\end{array}$ \\
\hline$s_{i}$ & $\begin{array}{l}\text { Probability of daily survival } \\
\text { period } t \text { given patch choice } i\end{array}$ & \multicolumn{2}{|c|}{$\begin{array}{l}\text { Calculated based on range of adult female survival in poor natural food production } \\
\text { year in Aspen as } s_{u}=0.75, s_{u i}=0.87 \text {, and } s_{w}=0.92 \text {, and later converted to daily } \\
\text { survival by raising to power of } 1 / 228\end{array}$} & $\begin{array}{l}\text { Baruch-Mordo (2012), } \\
\text { Appendix B }\end{array}$ \\
\hline$\phi(x)$ & $\begin{array}{l}\text { Terminal fitness function } \\
\text { at time } T\end{array}$ & \multicolumn{2}{|c|}{$\begin{array}{l}\text { Calculated based on allometric equation: } \exp \left(-0.61 M^{-0.25}\right) \text { where } M \text { is body mass, } \\
\text { or } \mathrm{kg} \text { fat times } 3\end{array}$} & McCarthy et al. (2008) \\
\hline \multirow[t]{5}{*}{$\lambda_{i j}$} & \multirow[t]{5}{*}{$\begin{array}{l}\text { Probability of finding food of } \\
\text { type } j \text { in patch } i\end{array}$} & \multicolumn{2}{|c|}{$\begin{array}{l}\text { A product of patch-specific food availability }\left(a_{i j}\right) \text { and composition }\left(c_{i j}\right) \text {. } \\
\text { Anthropogenic food } a_{i j} \text { obtained from field sampling and was: } 0.45 \text { in } u, 0.26 \text { in } u i \text {, } \\
\text { and } 0 \text { in w patches. Natural food } a_{i j} \text { in poor natural food year estimated from local } \\
\text { observations and was: } 0 \text { in } u, 0.1 \text { in } u i \text { and } w \text { patches. Anthropogenic food } c_{i j} \\
\text { estimated as: } 1 \text { in } u, 0.5 \text { in } u i \text {, and } 0 \text { in } w \text { patches. Natural food } c_{i j} \text { estimated as: } 0 \text { in } \\
\text { u, } 0.5 \text { in } u i \text {, and } 1 \text { in } w \text { patches. Multiplying composition and availability generated } \\
\text { the following } \lambda_{i j} \text { values: }\end{array}$} & Baruch-Mordo et al. (2011) \\
\hline & & Natural & Anthropogenic & \\
\hline & & Urban & 0.45 & \\
\hline & & Urban-interface & 0.13 & \\
\hline & & $\begin{array}{ll}\text { Wildland } & 0.1\end{array}$ & 0 & \\
\hline$\alpha_{i}(x)$ & $\begin{array}{l}\text { State-dependent cost of } \\
\text { movement in patch } i\end{array}$ & \multicolumn{2}{|c|}{$\begin{array}{l}\text { Body fat lost (kg/day) based on state-dependent basal metabolic rate, daily } \\
\text { distance moved in each patch (Appendix C), and kcal energy needed to lose } 1 \mathrm{~kg} \text { of } \\
\text { fat. Sample calculations available in Appendix D }\end{array}$} & $\begin{array}{l}\text { Baruch-Mordo, unpublished data, } \\
\text { Robbins (1993); Rode and Robbins } \\
\text { (2000); Tøien et al. (2011); Watts et al. } \\
\text { (1991) }\end{array}$ \\
\hline$Y_{i j}$ & $\begin{array}{l}\text { Yield from food } \\
\text { type } j \text { in patch } i\end{array}$ & \multicolumn{2}{|c|}{ Body fat gained ( $\mathrm{kg} /$ day) from natural $(0.5)$ and anthropogenic $(1.5)$ food sources } & $\begin{array}{l}\text { Baruch-Mordo and Noyce, } \\
\text { unpublished data, McLellan (2011) }\end{array}$ \\
\hline
\end{tabular}

competition that can lead to cub malnutrition and mortality (Robbins et al., 2012).

Range of female body mass for Aspen bears, $55-110 \mathrm{~kg}$, was within the range reported for black bears in Colorado (Beck, 1991). Because body mass of free-ranging black bears consists of approximately $30 \%$ fat at the end of hyperphagia season (Belant et al., 2006), we calculated the range of state variable $X(t)$ as the specified range in body mass divided by three, and used critical and cap values of 20 and $35 \mathrm{~kg}$ fat, respectively. We note that we conducted post hoc tests and found results to be robust even when setting the critical value equal to zero $\mathrm{kg}$ fat (Appendix A). We used methods of linear interpolation with $n=100$ as suggested by Clark and Mangel (2000), thus we incremented the state variable $\mathrm{kg}$ fat by 0.15 when evaluating the model.

We parameterized the terminal fitness function $\phi(x)$ using a log-linear allometric relationship between survival and body mass as: $\exp \left(-a M^{b} t\right)$, where $t$ is time interval and $a$ and $b$ are taxa-specific scaling parameters (McCarthy et al., 2008). We calculated $\phi(x)$ over a time interval of 1 day and converted the state variable value of $\mathrm{kg}$ fat $(x)$ back into total body mass $(M)$ by multiplying by three. We used the mean predicted values for $a(0.61)$ and $b(-0.25)$ reported for mammals, and conducted sensitivity analyses to examine model behavior given different values (Section 2.4). To guide parameterization of patch-specific survival, we used adult female survival in Aspen in poor natural food production years $(\hat{s}=0.718, S E=0.117$; Baruch-Mordo, 2012); we note that this survival estimate reflects both natural and human-caused mortality. We used exploratory analyses to identify a parameter space for patch-specific survival (Appendix B), and assigned default patchspecific survival as $0.75,0.87$, and 0.92 in urban, urban-interface, and wildland patches, respectively. We assessed uncertainty with sensitivity analysis detailed below (Section 2.4).

We calculated the probability of finding food as a function of the composition (comp $p_{i j}$ ) and availability ( avail $_{i j}$ ) of food type $j$ in patch $i$, such that $\lambda_{i j}=\operatorname{comp}_{i j} * a v a i l_{i j}$. We assumed wildland patches were composed only of natural foods and urban patches were composed only of anthropogenic foods. We used aerial photos to visually estimate, based on the ground cover of residential areas, the composition of natural and anthropogenic food sources as 50\% each in the urban-interface patches. We assigned zero availability to anthropogenic food sources (i.e., garbage) in wildland patches and to natural food sources in urban patches. Because we tested management scenarios occurring in poor natural food production years, we assumed natural food availability in urban-interface and wildland patches to be $10 \%$ (but see Section 2.4 ). We parameterized availability of garbage in urban and urban-interface patches using pre-treatment data collected in education and enforcement experiments (Baruch-Mordo et al., 2011), where mean garbage availability was 0.45 in downtown areas (urban patches) and 0.26 in residential neighborhoods (urban-interface patches). The resultant default probabilities of $\lambda_{i j}$ based on availability and composition values are presented in Table 1 .

We calculated state-dependent foraging $\operatorname{costs} \alpha_{i}(x)$ based on the amount of energy expended on movement in each patch converted into $\mathrm{kg}$ of fat loss. Watts et al. (1991) reported that polar bears (Ursus maritimus) used 12 times the energy of their basal metabolic rate $(B M R)$ to run at a speed of $2.2 \mathrm{~m} / \mathrm{s}$. We calculated $B M R$ as 33.12 times body mass $M$ based on an oxygen consumption formula for black bears $\left(0.276 \mathrm{ml} \mathrm{g}^{-1} \mathrm{~h}^{-1}\right.$; Tøien et al., 2011), which we converted to kcal using a factor of 5 ( $5 \mathrm{kcal}$ obtained from $1 \mathrm{~L}$ $\mathrm{O}_{2}$; Robbins, 1993). To obtain body mass $M$, we converted the state variable of $\mathrm{kg}$ fat back to body mass by multiplying by three. We converted the speed of $2.2 \mathrm{~m} / \mathrm{s}$ to $\mathrm{km} /$ day and divided $12 B M R$ by the result to provide a state-dependent estimate of the amount of kcal needed to move $1 \mathrm{~km}(\mathrm{kcal} / \mathrm{km})$. To obtain the daily energy expenditure on movement (kcal/day), we multiplied the energy expended per $\mathrm{km}$ by the mean daily distance moved in each patch as estimated from GPS data collected from Aspen bears (3.82, 3.67, and $6.16 \mathrm{~km} /$ day in urban, urban-interface, and wildland patches, respectively; Appendix C). Lastly to estimate $\mathrm{kg}$ of fat lost per day, we divided the daily energy expenditure by a conversion factor of $9110 \mathrm{kcal}$, which is the expected energy in $1 \mathrm{~kg}$ of bear fat (Rode and Robbins, 2000). Sample calculations for a bear with a state of $20 \mathrm{~kg}$ fat are provided in Appendix D.

Foraging benefits were based on the amount of $\mathrm{kg}$ fat gained from natural and anthropogenic foods. In British Columbia, wild black bears gained between 0.42 and $0.86 \mathrm{~kg}$ /day from natural food sources during summer (McLellan, 2011), which was within range 
of similar estimates reported for captive grizzly bears (Ursus arctos) fed on natural diets (Robbins et al., 2007). We found no published data of weight gain for bears feeding on anthropogenic resources; however unpublished data from Minnesota suggested free-ranging black bears that fed on anthropogenic food sources gained up to $2.3 \mathrm{~kg} /$ day in late summer and fall (K. Noyce, Minnesota Dept. of Natural Resources, personal communication), and in the Aspen study, one bear gained $1.5 \mathrm{~kg} /$ day in summer when feeding almost exclusively on garbage resources. Using the mid-point of the above reported ranges, we assumed a gain in body mass of $0.64 \mathrm{~kg} / \mathrm{day}$ from natural food sources and of $1.9 \mathrm{~kg} /$ day from anthropogenic foods. Given that in captive trials grizzly bears gained $0.79 \mathrm{~g}$ fat for each $1 \mathrm{~g}$ of body mass on low protein diets (Felicetti et al., 2003), we converted yields from $\mathrm{kg} /$ day to $\mathrm{kg}$ fat/day using a factor of 0.79 . Yield was therefore $0.5 \mathrm{~kg}$ fat/day from natural and $1.5 \mathrm{~kg}$ fat/day from anthropogenic foods, and we tested uncertainty in yield values selected (Section 2.4).

\subsection{Model implementation and sensitivity analyses}

The goal of this study was to find thresholds of benefit reduction and cost increase beyond which bears did not select urban and urban-interface patches. We tested effects of management strategies by incrementally reducing benefits or increasing costs in human-dominated patches. For benefit reduction we reduced availability of anthropogenic foods (avail ${ }_{\text {anthro }}$ ) in urban and urban-interface patches. For cost increase we assumed as mentioned above that the key response to aversive conditioning treatments of bears is flight behavior, thus we increased the $\mathrm{km}$ moved per day in each patch which subsequently increased the state-dependent energetic cost $\alpha_{i}(x)$. We note that under this approach the default cost parameter values (i.e., status quo with current management actions) reflected movement for foraging activity, and interactions with conspecifics and humans. We acknowledge that additional fitness costs due to aversive conditioning treatments may occur, but to the best of our knowledge no additional energetic data exist to parameterize our model. We also acknowledge that fitness costs due to lethal control are implicit in the lower survival in humandominated patches, but we focused our evaluation here on the energetic costs of aversive conditioning treatments.

We ran benefit reduction and cost increase scenarios and consecutively incremented parameter values by $5 \%$ of the previous value up to $100 \%$ reduction or increase of default value. For example, a $10 \%$ reduction in anthropogenic food availability (default values of 0.45 in urban and 0.26 in urban-interface patches) resulted in availability of 0.405 and 0.234 in human-dominated patches and reduced $\lambda_{\text {i anthro }}$. A $10 \%$ increase in cost resulted in movements of $4.20,4.04$, and $6.78 \mathrm{~km} /$ day in urban, urban-interface, and wildland patches (default values of $3.82,3.67$, and 6.16) and increased $\alpha_{i}(x)$. For each benefit reduction and cost increase iteration, we solved Eq. (2) across all time steps and kept records of patch selection. We defined threshold of benefit reduction and cost increase as the minimum percent reduction or increase that resulted in no selection of human-dominated patches, and we searched for state-dependent thresholds under each scenario. We implemented all analyses in program R ( $R$ Development Core Team, 2011).

We conducted sensitivity analyses to assess impacts of uncertainty in the following default parameters: (1) scaling parameters $a$ and $b$ for the terminal fitness function $\phi(x),(2)$ availability of natural food sources in a poor natural food production year (avail ${ }_{\text {natu- }}$ ral), (3) yield from anthropogenic foods $\left(Y_{\text {anthro }}\right)$, and (4) patchspecific survival $\left(s_{u}, s_{u i}\right.$, and $\left.s_{w}\right)$. We used Latin hypercube sampling (LHS) to sample random sets of parameter combinations following methodologies of Blower and Dowlatabadi (1994). We sampled from a normal distribution for the scaling parameters $a$ and $b$, where we estimated mean and SD for each using the reported pos- terior distribution for mammals in McCarthy et al. (2008). We used uniform distributions for all other parameters where we set the lower and upper distribution limits as: 0.05 and 0.25 for avail $_{\text {natural, }}$, 1.2 and 1.8 for $Y_{\text {anthro, }}$ and 0.5 and 1.0 for $s_{u}$. Limits for avail $l_{\text {natural }}$ were chosen to mimic a poor natural food year with only $5-25 \%$ of natural food availability based on personal observations of authors and local wildlife managers (K. Wright, Colorado Parks and Wildlife, personal communication). Limits for $Y_{\text {anthro }}$ were based on data obtained from literature and the field, i.e., $Y_{\text {anthro }}$ bound between the lowest and highest reported weight gain from anthropogenic foods, and multiplied by a $\mathrm{kg}$ weight to $\mathrm{kg}$ fat conversion factor of 0.79 (Section 2.3). We used limits for $s_{u}$ based on the range of adult female survival in poor years and using combinations of patch-specific survival values that resulted in realistic model behavior (Appendix B). Hence, we randomly drew a value between 0.03 and 0.21 for the difference $s_{u i}-s_{u}$ to calculate $s_{u i}$, and conditional on that we randomly drew a value between 0.01 and 0.09 for the difference $s_{w}-s_{u i}$ to calculate $s_{w}$. We tested whether drawing first the difference between $s_{u i}-s_{u}$ or between $s_{w}-s_{u i}$ changed sensitivity results and found results to be robust, hence we show only results for drawing difference of $s_{u i}-s_{u}$ first. We generated a total of 150 LHS sets, but we ran only 115 sets after limiting $s_{u i}$ and $s_{w}$ to $\leqslant 1.0$.

We assessed the influence of each parameter on model output by comparing the partial-rank correlation coefficients (PRCC) for the seven parameters $\left(a, b\right.$, avail natural, $Y_{\text {anthro }}, s_{u}, s_{u i}$, and $\left.s_{w}\right)$. PRCC allow evaluation of the relationships between the input parameters and response variable while accounting for any correlations between the input parameters (Hamby, 1995). A positive or negative PRCC value respectively indicated an increase or decrease in threshold value with an increase in the parameter values. We evaluated PRCC for thresholds in urban and urban-interface patches under both benefit reduction and cost increase scenarios and for each state.

\section{Results}

At default parameter values (i.e., no benefit reduction or cost increase), bears with high fat reserves foraged exclusively in wildland patches and bears with low fat reserves foraged exclusively in urban patches (Fig. 2A). The optimization strategy for all other bears was to stay in the safer patches with higher survival until later in the hyperphagia season when selection shifted to riskier patches with lower survival but higher yield (e.g., from wildland to urban-interface patch, or from urban-interface to urban patch).

When default availability of anthropogenic food sources was reduced by at least $55 \%$ in urban patches and $70 \%$ in urban-interface patches, all bears with fat reserves of $\geqslant 22.7 \mathrm{~kg}$ foraged exclusively in the wildland patch and thus avoided human-dominated patches (Fig. 2B and Fig. 3 top panels). Results varied by state where fatter bears had lower thresholds compared with bears of low fat reserves, and where bears with fat reserves $>34.4 \mathrm{~kg}$, which never foraged in human-dominated patches to begin with, had zero threshold values (Fig. 3). While reduction in anthropogenic food availability in urban and urban-interface patches did not eliminate use of urban patches by bears with $<22.7 \mathrm{~kg}$ fat, over-all selection of the urban patch decreased. Additionally, timing of selection of also changed; bears selected the urban patch early in the hyperphagia season, then switched to wildland patch after a few weeks, and finally selected the urban patch again towards the end of the season (Fig. 2B). Completely eliminating anthropogenic food availability in urban and urban-interface patches resulted in selection of only the urban-interface patches by bears of lower fat reserves.

We ran the cost increase scenarios for up to a $100 \%$ increase in costs due to movement in human-dominated patches and identi- 


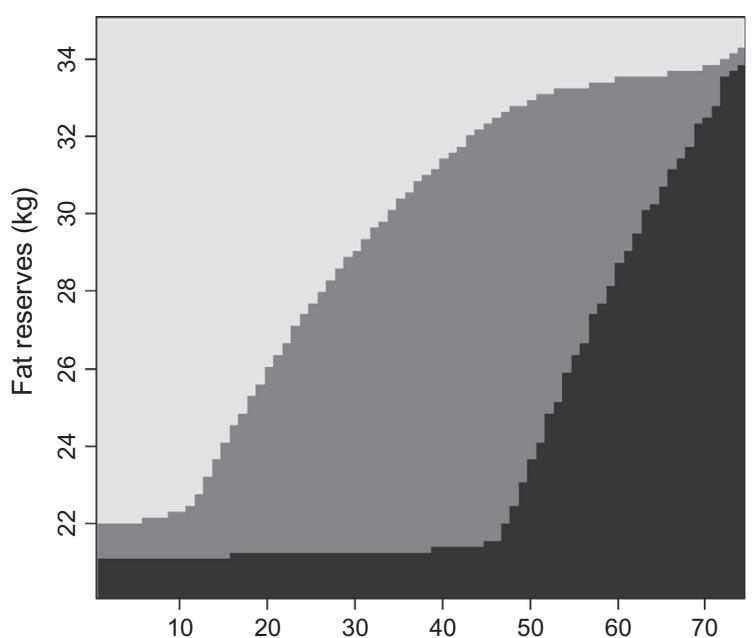

(A)

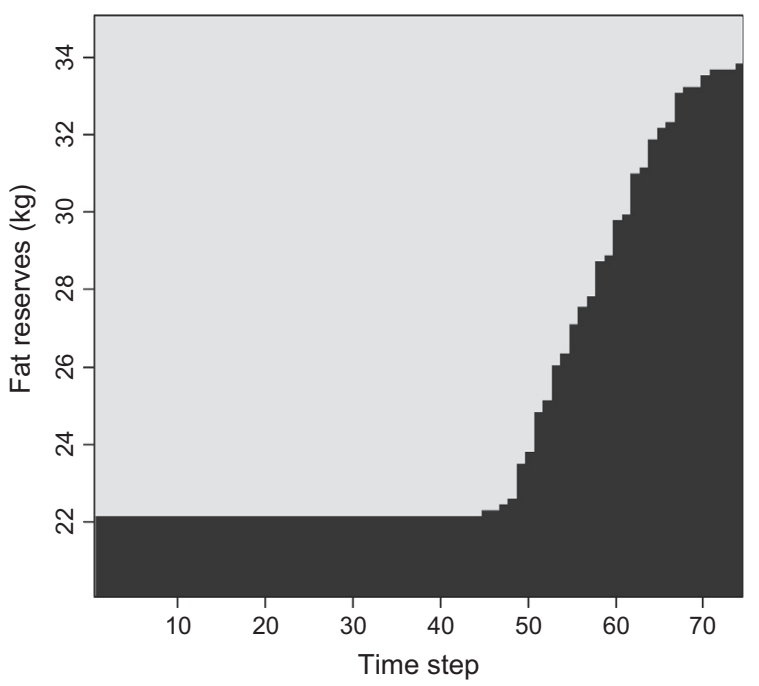

(C)

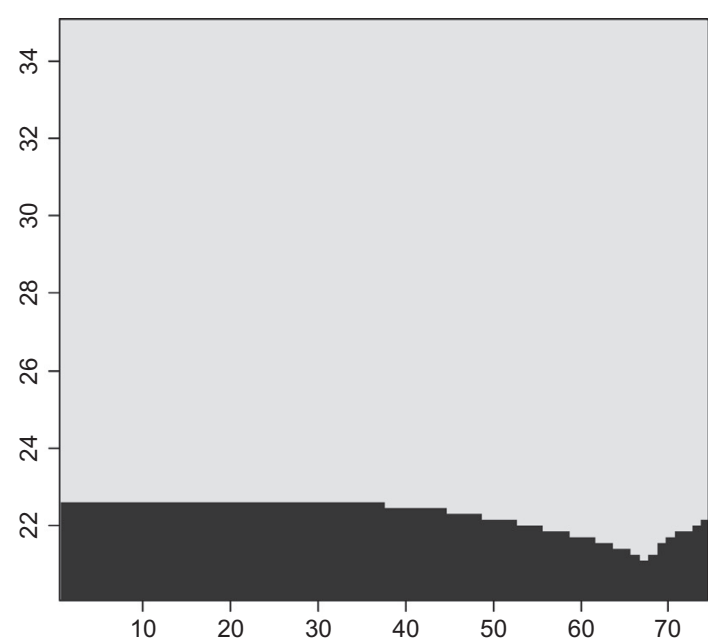

(B)

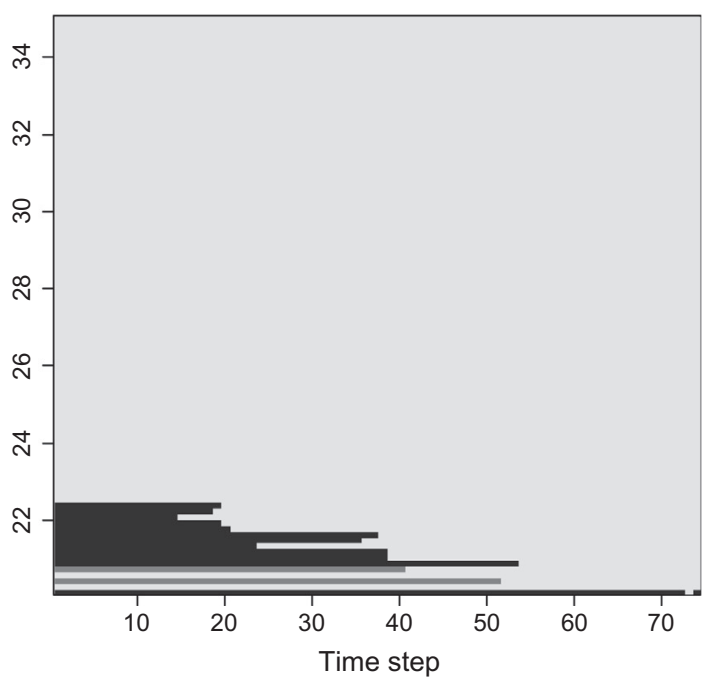

(D)

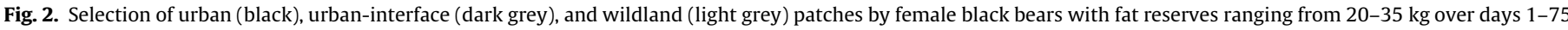

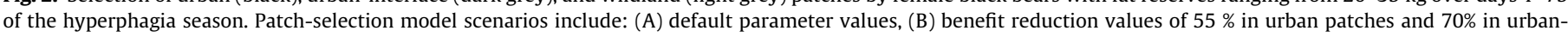

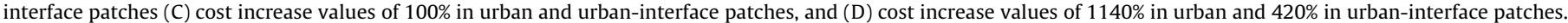

fied thresholds only for bears with a state $\geqslant 33.95 \mathrm{~kg}$ fat reserves. At cost increases of $100 \%$ in both urban and urban-interface patches, selection of human-dominated patches consisted only of urban patches (Fig. 2C). We continued to increase movement by $100 \%$ intervals and found that when cost increased by $>1100 \%$ of default value in the urban patch and $>400 \%$ in the urban-interface patch, cost increase thresholds had similar exclusion properties as the benefit reduction thresholds, i.e., bears of $\geqslant 22.7 \mathrm{~kg}$ fat reserves did not select human-dominated patches (Fig. 3 bottom panels). Similar to patterns observed with the benefit reduction scenarios, dynamics changed to selection of human-dominated patches earlier in the hyperphagia season at those thresholds (Fig. 2D). Exclusion of all bears, including those with lowest fat reserves, occurred only when costs increased by $2750 \%$ in the urban patch and $2000 \%$ in the urban-interface patch.

Sensitivity of thresholds to parameter uncertainty varied by state, with bears of very low (e.g., <22.7) or very high (e.g., $>34.4$ ) fat reserves being relatively less sensitive because they mostly had no or zero threshold values at default parameter values. We therefore focused result interpretation on bears with states $\geqslant 22.7$ and $\leqslant 34.4$ (Appendix E). Benefit reduction thresholds were more sensitive to changes in the scaling parameter $a$ rather than $b$ of the terminal fitness function (Fig. E1 panels A-C). In general, threshold values increased with an increase in $a$ and $Y_{\text {anthro }}$ and decreased with an increase in avail $_{\text {natural }}$. Threshold values in urban and urban-interface patches were more sensitive to their own patch-specific survival with a positive correlation, and thresholds in both patches were inversely correlated to survival in wildland patch. Sensitivity results for cost increase thresholds had similar trends as the benefit reduction thresholds (Fig. E1 panels D-F).

\section{Discussion}

Structured decision making is called for when evaluating the efficacy of mitigation strategies for human-wildlife conflict (Barlow et al., 2010). A crucial component is the understanding of ecological mechanisms that lead wildlife to conflict with humans. Acquiring such knowledge through field studies can be expensive, 

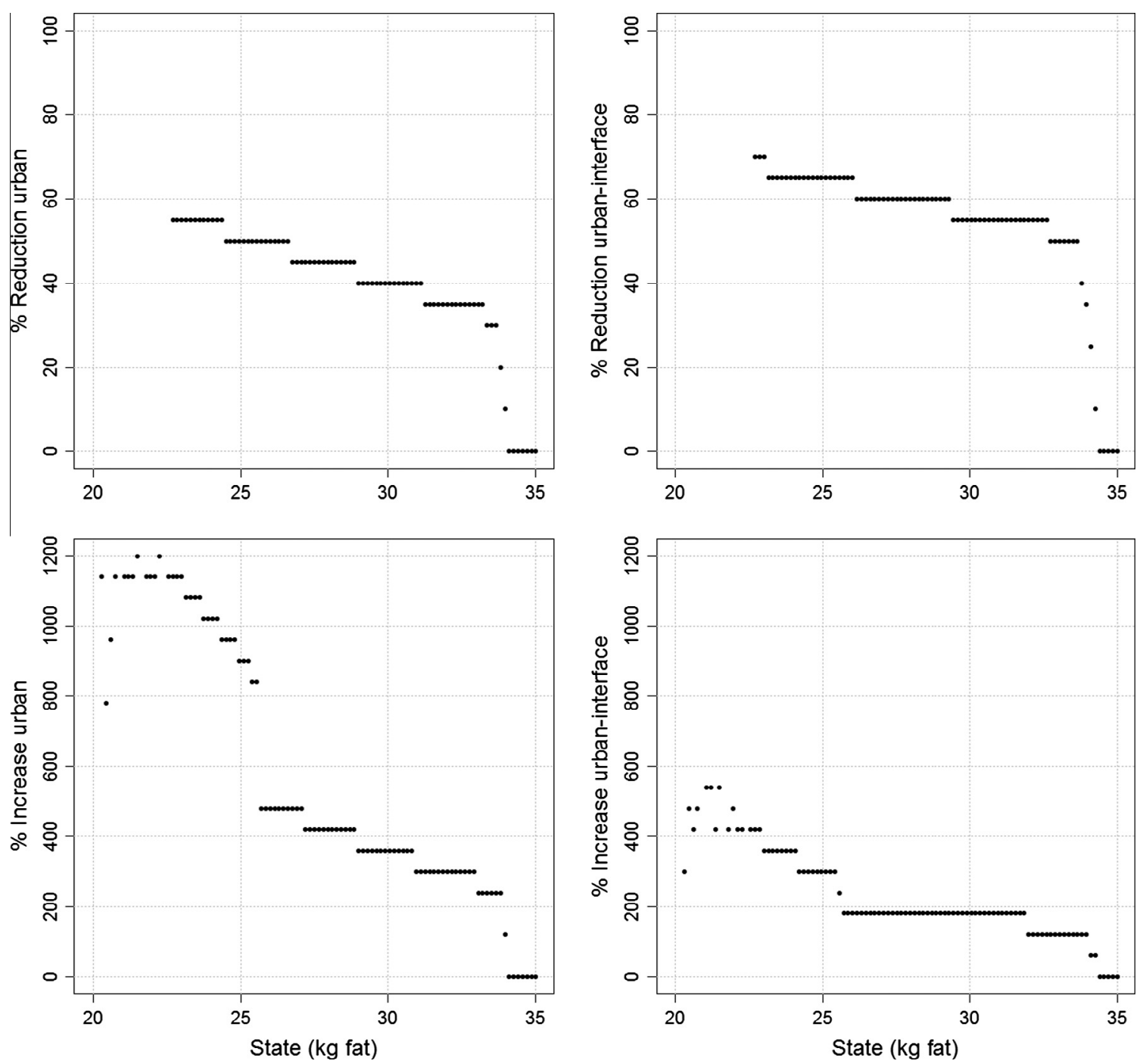

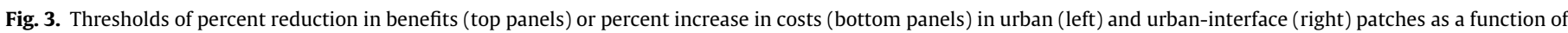
bear state. For each state ( $\mathrm{kg}$ fat), threshold values represent \% reduction or increase beyond which bears of that state did not select human-dominated patches.

and results are often not available in a timely manner to guide the mitigation of pressing conflicts, especially when managing species of conservation concern (e.g., tiger [Panthera tigris]). In this study we used patch-selection models to understand wildlife response to management aimed at reducing benefits and increasing costs of foraging in human-dominated areas. Implementing the model for black bear foraging in an urban system, we identified potential thresholds beyond which most bears should avoid human-dominated patches and gained insights on shifts in selection dynamics that can result from management. We therefore demonstrated how patch selection models can be a valuable decision making tool to study the effects of management on wildlife behavior and provide guidelines for conflict mitigation. Predictions from such models can also serve as hypotheses to be tested in an adaptive management framework (Grantham et al., 2010).

In our model system we found that benefit reduction thresholds of at least $70 \%$ excluded all bears from human-dominated patches except those with the lowest body fat reserves. The direct management implication is that the identified thresholds can provide guidelines for management in developing objectives to reduce anthropogenic attractants to bears in the study system. We also found that even when anthropogenic attractants are successfully eliminated, bears with low fat reserves continued to select hu- man-dominated patches, specifically the urban-interface patch that provided a mix of natural and anthropogenic food sources. However, this result was an artifact of the fact that we reduced anthropogenic food availability but did not simultaneously increase the patch-specific distance needed to move in order to find food. Because the daily movement distances were lower in urbaninterface compared to wildland patches, bears used the urbaninterface patch even when no anthropogenic food was available, and the observed results were an artifact of lower movement costs in that patch. When we adjusted the movement parameter to equal that of wildland patch, all bears foraged exclusively in wildland patches when anthropogenic food sources were eliminated, suggesting that such management strategy has the potential to successfully exclude bears from foraging in human-dominated patches.

Cost increase thresholds were at times an order of magnitude higher than default values, requiring an increase of bear movement in the urban and urban-interface patch by approximately 15 and $45 \mathrm{~km} /$ day to achieve similar exclusion results as the benefit reduction thresholds. While a detailed economic cost-benefit analysis for each management strategy is warranted (Hughey et al., 2003), it is likely not feasible to implement such high level costs using aversive conditioning treatments. Therefore, in this study 
system we would predict that implementing benefit reduction management strategy would be more effective than cost increase strategies. We note that we did not test the effects of various combinations of these strategies (e.g., $50 \%$ cost increase and 50\% benefit reduction), which may prove more efficient than only implementing benefit increase strategies and that future studies should explore. Also, it is possible that the cost increase parameters used in our models, i.e., the energetic costs of movement resulting from flight behavior, failed to incorporate other energetic costs associated with aversive conditioning treatments such as stress and increased vigilance behavior (Frid and Dill, 2002). However, those responses are difficult to quantify energetically, especially in a wild setting, and we were not aware of any data that allows incorporation of such parameters. Additionally field evaluations that likely included all behavioral responses by bears suggested that aversive conditioning treatments can be ineffective in deterring bears from human-dominated areas (Beckmann et al., 2004; Mazur, 2010).

Some authors advocate that preventative management, i.e., the reduction in benefits from anthropogenic attractants, should be the primary goal of conflict mitigation over reactive management, i.e., the lethal or non-lethal control of wildlife (Dorrance, 1983; Fall and Jackson, 2002). A key argument is that reactive management without an effective elimination of attractants can perpetuate the problem (Hristienko and McDonald, 2007). Others suggest that regardless of the food type consumed, wildlife that forage in human-dominated patches are habituated, pose danger to human safety, and therefore should be removed (Hristienko and McDonald, 2007). While resolving this philosophical difference in management views is beyond the scope of this paper, we demonstrated the advantages of patch selection models as a planning tool to assess impacts of each strategy in that they: (1) allow flexibility in model adaptations to address system-specific properties, e.g., the inclusion of multiple food types, (2) provide outputs that can serve as management objectives and research hypotheses, (3) allow measures of uncertainly using sensitivity analyses therefore compare the uncertainty resulting from each strategy, and (4) provide ecological insights on the mechanisms and dynamics of wildlife foraging decisions in response to human-wildlife conflict mitigation. Coupled with a socio-economic cost-benefit analysis, patch selection models can be a useful tool in the conservation managers' toolbox.

\section{Acknowledgements}

We thank the following for providing funding support: USDAWS-National Wildlife Research Center, Colorado Parks and Wildlife, Aspen Field Biology Lab, Berryman Institute, City of Aspen, Colorado Chapter of the Wildlife Society, Rocky Mountain Goats Foundation, Warner College of Natural Resources at Colorado State University, and Ms. M. Davis of Aspen, Colorado. We additionally thank the following individuals for their support and contribution: J. Broderick, J. Mao, and K. Wright of Colorado Parks and Wildlife, K. Crooks and D. Lewis of Colorado State University. Finally, we thank M. Buhnerkempe for sharing PRCC implementation code.

\section{Appendices A-E. Supplementary material}

Supplementary data associated with this article can be found, in the online version, at http://dx.doi.org/10.1016/j.biocon.2013. 02.002 .

\section{References}

Baker, S.E., Ellwood, S.A., Watkins, R., MacDonald, D.W., 2005. Non-lethal control of wildlife: using chemical repellents as feeding deterrents for the European badger Meles meles. J. Appl. Ecol. 42, 921-931.
Baker, P.J., Boitani, L., Harris, S., Saunders, G., White, P.C.L., 2008. Terrestrial carnivores and human food production: impact and management. Mammal Rev. 38, 123-166.

Barlow, A.C.D., Greenwood, C.J., Ahmad, I.U., Smith, J.L.D., 2010. Use of an actionselection framework for human-carnivore conflict in Bangladesh Sundrabans. Conserv. Biol. 24, 1338-1347.

Baruch-Mordo, S., 2012. Black bear ecology and human-bear interactions in an urban system. Ph.D. Thesis, Colorado State University, Fort Collins, Colorado, USA.

Baruch-Mordo, S., Breck, S.W., Wilson, K.R., Broderick, J., 2011. The carrot or the stick? Evaluation of education and enforcement as management tools for human-wildlife conflicts. PLoS ONE 6, e15681.

Baruch-Mordo, S., Breck, S.W., Wilson, K.R., Theobald, D.M., 2008. Spatiotemporal distributions of black bear-human conflicts in Colorado, USA. J. Wildlife Manage. 72, 1853-1862.

Beck, T.D.I., 1991. Black bears of west-central Colorado. Colorado Division of Wildlife Technical Publication No. 39, Fort Collins, Colorado, USA.

Beckmann, J.P., Berger, J., 2003. Rapid ecological and behavioural changes in carnivores: the responses of black bears (Ursus americanus) to altered food. J. Zool. (London) 26, 207-212.

Beckmann, J.P., Lackey, C.W., Berger, J., 2004. Evaluation of deterrent techniques and dogs to alter behavior of "nuisance" black bears. Wildlife Soc. Bull. 32, 11411146.

Beecham, J.J., Rohlman, J., 1994. A shadow in the forest: Idaho's black bear. University of Idaho Press, Idaho, USA.

Belant, J.L., Kielland, K., Follmann, E.H., Adams, L.G., 2006. Interspecific resource partitioning in sympatric ursids. Ecol. Appl. 16, 2333-2343.

Blower, S.M., Dowlatabadi, H., 1994. Sensitivity and uncertainty analysis of complex models of disease transmission: an HIV model, as an example. Int. Stat. Rev. 62, 229-243.

Clark, C.W., Mangel, M., 2000. Dynamic state variable models in ecology: methods and applications. Oxford University Press, New York, USA.

Conover, M.R., 2001. Resolving human-wildlife conflicts: the science of wildlife damage management. Lewis Publishers, Boca Raton, Florida, USA.

Dorrance, W.J., 1983. A philosophy of problem wildlife management. Wildlife Soc. Bull. 11, 319-324.

Eiler, J.H., Wathern, W.G., Pelton, M.R., 1989. Reproduction in black bears in the southern Appalachian Mountains. J. Wildlife Manage. 53, 962-968.

Fall, M.W., Jackson, W.B., 2002. The tools and techniques of wildlife damage management - changing needs: an introduction. Int. Biodeterior. Biodegrad. 49, 87-91.

Farley, S.D., Robbins, C.T., 1995. Lactation, hibernation, and mass dynamics of American black bears and grizzly bears. Can. J. Zool. 73, 2216-2222.

Felicetti, L.A., Robbins, C.T., Shipley, L.A., 2003. Dietary protein content alters energy expenditure and composition of the mass gain in grizzly bears (Ursus arctos horribilis). Physiol. Biochem. Zool. 76, 256-261.

Freedman, A.H., Portier, K.M., Sunquist, M.E., 2003. Life history analysis for black bears (Ursus americanus) in a changing demographic landscape. Ecol. Model. $167,47-64$.

Frid, A., Dill, L., 2002. Human-caused disturbance stimuli as a form of predation risk. Conserv. Ecol. 6, 11.

Geisser, H., Reyer, H.U., 2004. Efficacy of hunting, feeding, and fencing to reduce crop damage by wild boars. J. Wildlife Manage. 68, 939-946.

Grantham, H.S., Bode, M., McDonald-Madden, E., Game, E.T., Knight, A.T. Possingham, H.P., 2010. Effective conservation planning requires learning and adaptation. Front. Ecol. Environ. 8, 431-437.

Hamby, D.M., 1995. A comparison of sensitivity analysis techniques. Health Phys. $68,195-204$.

Harlow, H.J., Lohuis, T., Grogan, R.G., Beck, T.D.I., 2002. Body mass and lipid changes by hibernating reproductive and nonreproductive black bears (Ursus americanus). J. Mammal. 83, 1020-1025.

Honeyman, J., 2008. A retrospective evaluation of the effectiveness of aversive conditioning on grizzly bears in Peter Lougheed Provincial Park, Alberta, Canada. M.S. Thesis, Royal Roads University, Victoria, British Columbia, Canada.

Hopkins, J.B.I.I.I., Herrero, S., Shideler, R.T., Gunther, K.A., Schwartz, C.C., Kalinowski, S.T., 2010. A proposed lexicon of terms and concepts for human-bear management in North America. Ursus 21, 154-168.

Hristienko, H., McDonald Jr., J.E., 2007. Going into the 21st century: a perspective on trends and controversies in the management of the American black bear. Ursus $18,72-88$.

Hughey, K.F.D., Cullen, R., Moran, E., 2003. Integrating economics into priority setting and evaluation in conservation management. Conserv. Biol. 17, 93-103.

Jackson, R.M., Wangchuk, R., 2004. A community-based approach to mitigating livestock depredation by snow leopards. Hum. Dimensions Wildlife 9, 1-16.

Linnell, J.D., Aanes, R., Swenson, J.E., 1997. Translocation of carnivores as a method for managing problem animals: a review. Biodivers. Conserv. 6, 1245-1257.

Manfredo, M.J., 2008. Who cares about wildlife? Social science concepts for exploring human-wildlife relationships and conservation issues. Springer, New York, USA.

Mangel, M., Clark, C.W., 1986. Towards a unified foraging theory. Ecology 67, 11271138.

Mangel, M., Clark, C.W., 1988. Dynamic programming in behavioral ecology. Princeton University Press, Princeton, New Jersey, USA. 
Mattson, D.J., Blanchard, B.M., Knight, R.R., 1992. Yellowstone grizzly bear mortality, human habituation, and whitebark pine seed crops. J. Wildlife Manage. 56, 432442.

Mazur, R.L., 2010. Does aversive conditioning reduce human-black bear conflict? J. Wildlife Manage. 74, 48-54.

McCarthy, M.A., Citroen, R., McCall, S.C., 2008. Allometric scaling and Bayesian priors for annual survival of birds and mammals. Am. Nat. 172, 216-222.

McLellan, B.N., 2011. Implications of a high-energy and low-protein diet on the body composition, fitness, and competitive abilities of black (Ursus americanus) and grizzly (Ursus arctos) bears. Can. J. Zool. 89, 546-558.

Messmer, T.A., 2009. Human-wildlife conflicts: emerging challenges and opportunities. Human-wildlife Conflicts 3, 10-17.

Michalski, F., Boulhosa, R.L.P., Faria, A., Peres, C.A., 2006. Human-wildlife conflicts in a fragmented Amazonian forest landscape: determinants of large felid depredation on livestock. Anim. Conserv. 9, 179-188.

Mitchell, M.S., Pacifici, L.B., Grand, J.B., Powell, R.A., 2009. Contribution of vital rates to growth of a protected population of American black bears. Ursus 20 77-84.

Nelson, R. A., Folk, G.E., Jr., Pfeiffer, E.W., Craighead, J. Jonkel, C.J., Steiger, D.L. 1983. Behavior, biochemistry, and hibernation in black, grizzly, and polar bears. In: International Conference on Bear Research and Management, vol. 5, pp. 284 290.

R Development Core Team, 2011. R: A language and environment for statistical computing. R Foundation for Statistical Computing, Vienna, Austria. ISBN 3900051-07-0, <http://www.R-project.org/>

Robbins, CT, 1993. Wildlife Feeding and Nutrition. Academic Press, New York, USA

Robbins, C.T., Ben-David, M., Fortin, J.K., Nelson, O.L., 2012. Maternal condition determines birth date and growth of newborn bear cubs. J. Mammal. 93, 540546.

Robbins, C.T., Fortin, J.K., Rode, K.D., Farley, S.D., Shipley, L.A., Felicetti, L.A., 2007. Optimizing protein intake as a foraging strategy to maximize mass gain in an omnivore. Oikos 116, 1675-1682.
Rode, K.D., Robbins, C.T., 2000. Why bears consume mixed diets during fruit abundance. Can. J. Zool. 78, 1640-1645.

Ryan, C.W., Pack, J.C., Igo, K.W., Billings, A., 2007. Influence of mast production on black bear non-hunting mortalities in West Virginia. Ursus 18, 46-53.

Shivik, J.A., Treves, A., Callahan, P., 2003. Nonlethal techniques for managing predation: primary and secondary repellents. Conserv. Biol. 17, 1531-1537.

Shochat, E., 2004. Credit or debit? Resource input changes population dynamics of city-slicker birds. Oikos 106, 622-626.

Sitati, N.W., Walpole, M.J., Leader-Williams, N., 2005. Factors affecting susceptibility of farms to crop raiding by African elephants: using a predictive model to mitigate conflict. J. Appl. Ecol. 42, 1175-1182.

Spencer, R.D. Beausoleil, R.A. Martorello, D.A, 2007. How agencies respond to human-black bear conflicts: a survey of wildlife agencies in North America. Ursus 18, 217-229.

Tøien, Ø., Blake, J., Edgar, D.M., Grahn, D.A., Heller, H.C., Barnes, B.M., 2011. Hibernation in black bears: independence of metabolic suppression from body temperature. Science 331, 906-909.

Treves, A., Karanth, K.U., 2003. Human-carnivore conflict and perspectives on carnivore management worldwide. Conserv. Biol. 17, 1491-1499.

Watts, P.D., Ferguson, K.L., Draper, B.A., 1991. Energetic output of subadult polar bears (Ursus maritimus): resting, disturbance and locomotion. Comp. Biochem. Physiol. 98, 191-193.

Woodroffe, R., Thirgood, S., Rabinowitz, A. (Eds.), 2005. People and wildlife: conflict or coexistence? Cambridge University Press, Cambridge, UK.

Zack, C.S., Milne, B.T., Dunn, W.C., 2003. Southern oscillation index as an indicator of encounters between humans and black bears in New Mexico. Wildlife Soc. Bull. 31, 517-520. 